\title{
ON Modified $(\alpha-\eta)$-Contractive Mappings
}

\author{
Marwan Amin Kutbi, ${ }^{1}$ Muhammad Arshad, ${ }^{2}$ and Aftab Hussain ${ }^{2}$ \\ ${ }^{1}$ Department of Mathematics, King Abdulaziz University, Jeddah, Saudi Arabia \\ ${ }^{2}$ Department of Mathematics, International Islamic University, H-10, Islamabad 44000, Pakistan
}

Correspondence should be addressed to Muhammad Arshad; marshad_zia@yahoo.com

Received 6 May 2014; Accepted 6 July 2014; Published 21 July 2014

Academic Editor: Abdul Latif

Copyright (C) 2014 Marwan Amin Kutbi et al. This is an open access article distributed under the Creative Commons Attribution License, which permits unrestricted use, distribution, and reproduction in any medium, provided the original work is properly cited.

Hussain et al. (2013) established new fixed point results in complete metric space. In this paper, we prove fixed point results of $\alpha$ admissible mappings with respect to $\eta$, for modified contractive condition in complete metric space. An example is given to show the validity of our work. Our results generalize/improve several recent and classical results existing in the literature.

\section{Preliminaries and Scope}

The study of fixed point problems in nonlinear analysis has emerged as a powerful and very important tool in the last 60 years. Particularly, the technique of fixed point theory has been applicable to many diverse fields of sciences such as engineering, chemistry, biology, physics, and game theory. Over the years, fixed point theory has been generlized in many directions by several mathematicians (see [1-36]).

In 1973, Geraghty [12] studied different contractive conditions and established some useful fixed point theorems.

In 2012, Samet et al. [33] introduced a concept of $\alpha-$ $\psi$-contractive type mappings and established various fixed point theorems for mappings in complete metric spaces. Afterwards Karapinar and Samet [10] refined the notions and obtained various fixed point results. Hussain et al. [17] extended the concept of $\alpha$-admissible mappings and obtained useful fixed point theorems. Subsequently, Abdeljawad [4] introduced pairs of $\alpha$-admissible mappings satisfying new sufficient contractive conditions different from those in $[17,33]$ and proved fixed point and common fixed point theorems. Lately, Salimi et al. [32] modified the concept of $\alpha-$ $\psi$-contractive mappings and established fixed point results.

We define $\Omega$ the family of nondecreasing functions $\psi$ : $[0,+\infty) \rightarrow[0,+\infty)$ such that $\sum_{n=1}^{+\infty} \psi^{n}(t)<+\infty$, and $\psi(0)=$ 0 for each $t>0$ where $\psi^{n}$ is the $n$th term of $\psi$.

Lemma 1 (see [32]). If $\psi \in \Omega$, then $\psi(t)<t$ for all $t>0$.
Definition 2 (see [33]). Let $(X, d)$ be a metric space and let $S: X \rightarrow X$ be a given mapping. We say that $S$ is an $\alpha-\psi-$ contractive mapping if there exist two functions $\alpha: X \times X \rightarrow$ $[0,+\infty)$ and $\psi \in \Omega$ such that

$$
\alpha(x, y) d(S x, S y) \leq \psi(d(x, y)),
$$

for all $x, y \in X$

Definition 3 (see [33]). Let $S: X \rightarrow X$ and $\alpha: X \times X \rightarrow[0$, $+\infty)$. One says that $S$ is $\alpha$-admissible if $x, y \in X, \alpha(x, y) \geq$ $1 \Rightarrow \alpha(S x, S y) \geq 1$.

Example 4. Consider $X=[0, \infty)$. Define $S: X \rightarrow X$ and $\alpha$ : $X \times X \rightarrow[0, \infty)$ by $S x=2 x$, for all $x, y \in X$ and

$$
\alpha(x, y)= \begin{cases}e^{y / x} & \text { if } x \geq y, x \neq 0 \\ 0 & \text { if } x<y\end{cases}
$$

Then $S$ is $\alpha$-admissible.

Definition 5 (see [32]). Let $S: X \rightarrow X$ and let $\alpha, \eta: X \times X \rightarrow$ $[0,+\infty)$ be two functions. One says that $S$ is $\alpha$-admis-sible mapping with respect to $\eta$ if $x, y \in X, \alpha(x, y) \geq \eta(x, y) \Rightarrow$ $\alpha(S x, S y) \geq \eta(S x, S y)$. Note that if one takes $\eta(x, y)=1$, then this definition reduces to definition [33]. Also if we take $\alpha(x, y)=1$, then one says that $S$ is an $\eta$-subadmissible mapping. 


\section{Main Results}

In this section, we prove fixed point theorems for $\alpha$-admissible mappings with respect to $\eta$, satisfying modified $(\alpha-\eta)$ contractive condition in complete metric space.

Theorem 6. Let $(X, d)$ be a complete metric space and let $S$ is $\alpha$-admissible mappings with respect to $\eta$. Assume that there exists a function $\beta:[0,+\infty) \rightarrow[0,1)$ such that, for any bounded sequence $\left\{t_{n}\right\}$ of positive reals, $\beta\left(t_{n}\right) \rightarrow 1$ implies $t_{n} \rightarrow 0$ such that

$$
\begin{aligned}
& (d(S x, S y)+l)^{\alpha(x, S x) \alpha(y, S y)} \\
& \quad \leq(\beta(d(x, y)) d(x, y)+l)^{\eta(x, S x) \eta(y, S y)}
\end{aligned}
$$

for all $x, y \in X$ where $l \geq 1$; then suppose that one of the following holds:

(i) $S$ is continuous;

(ii) if $\left\{x_{n}\right\}$ is a sequence in $X$ such that $\alpha\left(x_{n}, x_{n+1}\right) \geq$ $\eta\left(x_{n}, x_{n+1}\right)$ for all $n \in \mathbb{N} \cup\{0\}$ and $x_{n} \rightarrow p \in X$ as $n \rightarrow+\infty$, then

$$
\alpha(p, S p) \geq \eta(p, S p)
$$

If there exists $x_{0}, x_{1} \in X$ such that $\alpha\left(x_{0}, x_{1}\right) \geq \eta\left(x_{0}, x_{1}\right)$, then $S$ has a unique fixed point.

Proof. Let $x_{0} \in X$ and define

$$
x_{n+1}=S x_{n}, \quad \forall n \geq 0 .
$$

We will assume that $x_{n} \neq x_{n+1}$ for each $n$. Otherwise, there exists an $n$ such that $x_{n}=x_{n+1}$. Then $x_{n}=S x_{n}$ and $x_{n}$ is a fixed point of $S$. Since $\alpha\left(x_{0}, x_{1}\right) \geq \eta\left(x_{0}, x_{1}\right)$ and $S$ is $\alpha$-admissible mapping with respect to $\eta$, we have

$$
\alpha\left(x_{1}, x_{2}\right)=\alpha\left(S x_{0}, S x_{1}\right) \geq \eta\left(S x_{0}, S x_{1}\right)=\eta\left(x_{1}, x_{2}\right) .
$$

By continuing in this way, we have

$$
\alpha\left(x_{n}, x_{n+1}\right) \geq \eta\left(x_{n}, x_{n+1}\right)
$$

for all $n \in \mathbb{N} \cup\{0\}$. From (7), we have

$$
\alpha\left(x_{n-1}, x_{n}\right) \alpha\left(x_{n}, x_{n+1}\right) \geq \eta\left(x_{n-1}, x_{n}\right) \eta\left(x_{n}, x_{n+1}\right) .
$$

Thus applying the inequality (3), with $x=x_{k-1}$ and $y=x_{k}$, we obtain

$$
\begin{aligned}
& \left(d\left(x_{k}, x_{k+1}\right)+l\right)^{\eta\left(x_{k-1}, S x_{k-1}\right) \eta\left(x_{k}, S x_{k}\right)} \\
& \quad=\left(d\left(S x_{k-1}, S x_{k}\right)+l\right)^{\eta\left(x_{k-1}, S x_{k-1}\right) \eta\left(x_{k}, S x_{k}\right)} \\
& \quad \leq\left(d\left(S x_{k-1}, S x_{k}\right)+l\right)^{\alpha\left(x_{k-1}, S x_{k-1}\right) \alpha\left(x_{k}, S x_{k}\right)} \\
& \quad \leq\left(\beta\left(d\left(x_{k-1}, x_{k}\right)\right) d\left(x_{k-1}, x_{k}\right)+l\right)^{\eta\left(x_{k-1}, S x_{k-1}\right) \eta\left(x_{k}, S x_{k}\right)}
\end{aligned}
$$

which implies that

$$
d\left(x_{k}, x_{k+1}\right) \leq \beta\left(d\left(x_{k-1}, x_{k}\right)\right) d\left(x_{k-1}, x_{k}\right) .
$$

We suppose that

$$
d\left(x_{k}, x_{k+1}\right) \leq d\left(x_{k-1}, x_{k}\right) .
$$

Then we prove that $d\left(x_{k-1}, x_{k}\right) \rightarrow 0$. It is clear that $\left\{d\left(x_{k-1}\right.\right.$, $\left.\left.x_{k}\right)\right\}$ is a decreasing sequence. Therefore, there exists some positive number $\varrho$ such that $\lim _{n \rightarrow \infty} d\left(x_{k}, x_{k+1}\right)=\varrho$. Now we will prove that $\varrho=0$. From (10), we have

$$
\frac{d\left(x_{k}, x_{k+1}\right)}{d\left(x_{k-1}, x_{k}\right)} \leq \beta\left(d\left(x_{k-1}, x_{k}\right)\right) \leq 1 .
$$

Now by taking limit $k \rightarrow \infty$, we have

$$
\begin{gathered}
1=\frac{d}{d}=\frac{\lim _{k \rightarrow \infty} d\left(x_{k}, x_{k+1}\right)}{\lim _{k \rightarrow \infty} d\left(x_{k-1}, x_{k}\right)} \leq \beta\left(d\left(x_{k-1}, x_{k}\right)\right) \leq 1, \\
\lim _{k \rightarrow \infty} \beta\left(d\left(x_{k-1}, x_{k}\right)\right)=1 .
\end{gathered}
$$

By using property of $\beta$ function, we have $\lim _{k \rightarrow \infty} d\left(x_{k-1}\right.$, $\left.x_{k}\right)=0$. Thus

$$
\lim _{k \rightarrow \infty} d\left(x_{k}, x_{k+1}\right)=0 .
$$

Now we prove that sequence $\left\{x_{n}\right\}$ is Cauchy sequence. Suppose on contrary that $\left\{x_{n}\right\}$ is not a Cauchy sequence. Then there exists $\epsilon>0$ and sequences $\left\{x_{m_{k}}\right\}$ and $\left\{x_{n_{k}}\right\}$ such that, for all positive integers $k$, we have $n_{k}>m_{k}>k$,

$$
\begin{gathered}
d\left(x_{m_{k}}, x_{n_{k}}\right) \geq \epsilon, \\
d\left(x_{m_{k}}, x_{n_{k-1}}\right)<\epsilon .
\end{gathered}
$$

By the triangle inequality, we have

$$
\begin{aligned}
\epsilon & \leq d\left(x_{m_{k}}, x_{n_{k}}\right) \\
& \leq d\left(x_{m_{k}}, x_{n_{k-1}}\right)+d\left(x_{n_{k-1}}, x_{n_{k}}\right) \\
& <\epsilon+d\left(x_{n_{k-1}}, x_{n_{k}}\right)
\end{aligned}
$$

for all $k \in \mathbb{N}$. Now taking limit as $k \rightarrow+\infty$ in (16) and using (14), we have

$$
\lim _{k \rightarrow \infty} d\left(x_{m_{k}}, x_{n_{k}}\right)=\epsilon
$$

Again using triangle inequality, we have

$$
\begin{aligned}
d\left(x_{m_{k}}, x_{n_{k}}\right) \leq & d\left(x_{m_{k}}, x_{m_{k+1}}\right)+d\left(x_{m_{k+1}}, x_{n_{k+1}}\right) \\
& +d\left(x_{n_{k+1}}, x_{n_{k}}\right), \\
d\left(x_{m_{k+1}}, x_{n_{k+1}}\right) \leq & d\left(x_{m_{k+1}}, x_{m_{k}}\right)+d\left(x_{m_{k}}, x_{n_{k}}\right) \\
& +d\left(x_{n_{k}}, x_{n_{k+1}}\right) .
\end{aligned}
$$

Taking limit as $k \rightarrow+\infty$ and using (14) and (17), we obtain

$$
\lim _{k \rightarrow+\infty} d\left(x_{m_{k+1}}, x_{n_{k+1}}\right)=\epsilon .
$$


By using (3), (17), and (19), we have

$$
\begin{aligned}
& \left(d\left(x_{m_{k+1}}, x_{n_{k+1}}\right)+l\right)^{\eta\left(x_{m_{k}}, S x_{m_{k}}\right) \eta\left(x_{n_{k}}, S x_{n_{k}}\right)} \\
& \quad \leq\left(d\left(x_{m_{k+1}}, x_{n_{k+1}}\right)+l\right)^{\alpha\left(x_{m_{k}}, S x_{m_{k}}\right) \alpha\left(x_{n_{k}}, S x_{n_{k}}\right)} \\
& \quad \leq\left(d\left(S x_{m_{k}}, T x_{n_{k}}\right)+l\right)^{\alpha\left(x_{m_{k}}, S x_{m_{k}}\right) \alpha\left(x_{n_{k}}, S x_{n_{k}}\right)} \\
& \quad \leq\left(\beta\left(d\left(x_{m_{k}}, x_{n_{k}}\right)\right) d\left(x_{m_{k}}, x_{n_{k}}\right)+l\right)^{\eta\left(x_{m_{k}}, S x_{m_{k}}\right) \eta\left(x_{n_{k}}, S x_{n_{k}}\right)}
\end{aligned}
$$

which implies that

$$
d\left(x_{m_{k+1}}, x_{n_{k+1}}\right) \leq \beta\left(d\left(x_{m_{k}}, x_{n_{k}}\right)\right) d\left(x_{m_{k}}, x_{n_{k}}\right) .
$$

Therefore, we have

$$
\frac{d\left(x_{m_{k+1}}, x_{n_{k+1}}\right)}{d\left(x_{m_{k}}, x_{n_{k}}\right)} \leq \beta\left(d\left(x_{m_{k}}, x_{n_{k}}\right)\right) \leq 1 .
$$

Now taking limit as $k \rightarrow+\infty$ in (22), we get

$$
\lim _{n \rightarrow \infty} \beta\left(d\left(x_{m_{k}}, x_{n_{k}}\right)\right)=1 \text {. }
$$

Hence $\lim _{k \rightarrow \infty} d\left(x_{m_{k}}, x_{n_{k}}\right)=0<\epsilon$, which is a contradiction. Hence $\left\{x_{n}\right\}$ is a Cauchy sequence. Since $X$ is complete so there exists $p \in X$ such that $x_{n} \rightarrow p$. Now we prove that $p=S p$. Suppose (i) holds; that is, $S$ is continuous, so we get

$$
S p=S \lim _{n \rightarrow \infty} x_{n}=\lim _{n \rightarrow \infty} S x_{n}=\lim _{n \rightarrow \infty} x_{n+1}=p .
$$

Thus $p=S p$. Now we suppose that (ii) holds. Since

$$
\alpha\left(x_{n}, x_{n+1}\right) \geq \eta\left(x_{n}, x_{n+1}\right)
$$

for all $n \in \mathbb{N} \cup\{0\}$. By the hypotheses of (ii), we have

$$
\alpha(p, S p) \alpha\left(x_{k}, S x_{k}\right) \geq \eta(p, S p) \eta\left(x_{k}, S x_{k}\right) .
$$

Using the triangle inequality and (3), we have

$$
\begin{aligned}
(d & \left.\left(S p, x_{k+1}\right)+l\right)^{\eta(p, S p) \eta\left(x_{k}, S x_{k}\right)} \\
& =\left(d\left(S p, S x_{k}\right)+l\right)^{\eta(p, S p) \eta\left(x_{k}, S x_{k}\right)} \\
& \leq\left(d\left(S p, S x_{k}\right)+l\right)^{\alpha(p, S p) \alpha\left(x_{k}, S x_{k}\right)} \\
& \leq\left(\beta\left(d\left(p, x_{k}\right)\right) d\left(p, x_{k}\right)+l\right)^{\eta(p, S p) \eta\left(x_{k}, S x_{k}\right)}
\end{aligned}
$$

which implies that

$$
d\left(S p, x_{k+1}\right) \leq \beta\left(d\left(p, x_{k}\right)\right) d\left(p, x_{k}\right) .
$$

Letting $k \rightarrow \infty$ then we have $d(p, S p)=0$. Thus $p=S p$. Let there exists $q$ to be another fixed point of $S q \in X$, s.t $q=S q$;

$$
\begin{aligned}
& (d(p, q)+l)^{\eta(p, S p) \eta(q, S q)} \\
& \quad=(d(S p, S q)+l)^{\eta(p, S p) \eta(q, S q)} \\
& \quad \leq(d(S p, S q)+l)^{\alpha(p, S p) \alpha(q, S q)} \\
& \quad \leq(\beta(d(p, q)) d(p, q)+l)^{\eta(p, S p) \eta(q, S q)}
\end{aligned}
$$

which implies that

$$
d(p, q)+l \leq \beta(d(p, q)) d(p, q)+l .
$$

By the property of $\beta$ function, $\beta(d(p, q))=1$, implies $d(p$, $q)=0$; then we have $p=q$. Hence $S$ has a unique fixed point. lary.

If $\eta(x, y)=1$ in Theorem 6 , we get the following corol-

Corollary 7 (see [17]). Let $(X, d)$ be a complete metric space and let $S$ be $\alpha$-admissible mapping. Assume that there exists a function $\beta:[0,+\infty) \rightarrow[0,1)$ such that, for any bounded sequence $\left\{t_{n}\right\}$ of positive reals, $\beta\left(t_{n}\right) \rightarrow 1$ implies $t_{n} \rightarrow 0$ such that

$$
(d(S x, S y)+l)^{\alpha(x, S x) \alpha(y, S y)} \leq \beta(d(x, y)) d(x, y)+l,
$$

for all $x, y \in X$, where $l \geq 1$. Suppose that either

(i) $S$ is continuous, or

(ii) if $\left\{x_{n}\right\}$ is a sequence in $X$ such that $\alpha\left(x_{n}, x_{n+1}\right) \geq 1$ for all $n \in \mathbb{N} \cup\{0\}$ and $x_{n} \rightarrow p \in X$ as $n \rightarrow+\infty$, then

$$
\alpha(p, S p) \geq 1 \text {. }
$$

If there exists $x_{0}, x_{1} \in X$ such that $\alpha\left(x_{0}, x_{1}\right) \geq 1$; then $S$ has a fixed point. lary.

If $\alpha(x, y)=1$ in Theorem 6 , we get the following corol-

Corollary 8. Let $(X, d)$ be a complete metric space and let $S$ be $\eta$-subadmissible mapping. Assume that there exists a function $\beta:[0,+\infty) \rightarrow[0,1)$ such that, for any bounded sequence $\left\{t_{n}\right\}$ of positive reals, $\beta\left(t_{n}\right) \rightarrow 1$ implies $t_{n} \rightarrow 0$ such that

$$
(d(S x, S y)+l) \leq(\beta(d(x, y)) d(x, y)+l)^{\eta(x, S x) \eta(y, S y)}
$$

for all $x, y \in X$ where $l \geq 1$; then suppose that one of the following holds:

(i) $S$ is continuous;

(ii) if $\left\{x_{n}\right\}$ is a sequence in $X$ such that $\eta\left(x_{n}, x_{n+1}\right) \leq 1$ for all $n \in \mathbb{N} \cup\{0\}$ and $x_{n} \rightarrow p \in X$ as $n \rightarrow+\infty$, then

$$
\eta(p, S p) \leq 1 \text {. }
$$

If there exists $x_{0}, x_{1} \in X$ such that $\eta\left(x_{0}, x_{1}\right) \leq 1$, then $S$ has a fixed point.

Example 9. Let $X=[0, \infty)$ with usual metric $d(x, y)=|x-y|$ for all $x, y \in X$ and $S: X \rightarrow X, \alpha: X \times X \rightarrow[0, \infty)$ and $\beta:[0,+\infty) \rightarrow[0,1]$ for all $x, y \in X$ be defined by

$$
\begin{aligned}
& S x=\left\{\begin{array}{ll}
0 & \text { if } x \in[0,1] \\
\sqrt{x} & \text { if } x \in(1,5]
\end{array},\right. \\
& \alpha(x, y)=\left\{\begin{array}{ll}
1 & \text { if } x \geq y \\
0 & \text { if } x<y
\end{array},\right. \\
& \beta(t)=\frac{1}{\sqrt{t}}, \quad \beta(0) \in[0,1] .
\end{aligned}
$$


We prove that Corollary 7 can be applied to $S$. Let $x, y \in X$; clearly $S x \leq x$ and $S y \leq y$, then $S$ of $\alpha$-admissible mapping $\alpha(x, y) \geq 1$, and $\alpha(x, S x) \geq 1, \alpha(y, S y) \geq 1$, and $\alpha(x$, $S x) \alpha(y, S y) \geq 1$ imply that

$$
\begin{aligned}
& (d(S x, S y)+l)^{\alpha(x, S x) \alpha(y, S y)} \\
& \quad=S x-S y+l=\sqrt{x}-\sqrt{y}+l \leq \frac{x-y}{\sqrt{x}+\sqrt{y}}+l \\
& \quad \leq \frac{2(x-y)}{3 \sqrt{x-y}}+l=\beta(d(x, y))(d(x, y))+l .
\end{aligned}
$$

If $\alpha(x, S x) \alpha(y, S y)=0$, then we have

$$
\begin{aligned}
& (d(S x, S y)+l)^{\alpha(x, S x) \alpha(y, S y)} \\
& \quad=1 \leq \beta(d(x, y))(d(x, y))+l .
\end{aligned}
$$

Let $x=5$ and $y=2$; then

$$
\begin{aligned}
& d(S 5, S 2)^{\alpha(5, S 5) \alpha(3, S 3)} \\
& \quad=0.8218 \\
& \quad \leq \beta(d(5,3))(d(5,3)) \\
& \quad=1.4142 .
\end{aligned}
$$

Theorem 10. Let $(X, d)$ be a complete metric space and let $S$ be $\alpha$-admissible mappings with respect to $\eta$. Assume that there exists a function $\beta:[0,+\infty) \rightarrow[0,1)$ such that, for any bounded sequence $\left\{t_{n}\right\}$ of positive reals, $\beta\left(t_{n}\right) \rightarrow 1$ implies $t_{n} \rightarrow 0$ such that

$$
\begin{aligned}
& \alpha(x, S x) \alpha(y, S y) d(S x, S y) \\
& \quad \leq \eta(x, S x) \eta(y, S y) \beta(d(x, y)) d(x, y)
\end{aligned}
$$

for all $x, y \in X$; then suppose that one of the following holds:

(i) $S$ is continuous;

(ii) if $\left\{x_{n}\right\}$ is a sequence in $X$ such that $\alpha\left(x_{n}, x_{n+1}\right) \geq$ $\eta\left(x_{n}, x_{n+1}\right)$ for all $n \in \mathbb{N} \cup\{0\}$ and $x_{n} \rightarrow p \in X$ as $n \rightarrow+\infty$, then

$$
\alpha(p, S p) \geq \eta(p, S p)
$$

If there exists $x_{0}, x_{1} \in X$ such that $\alpha\left(x_{0}, x_{1}\right) \geq \eta\left(x_{0}, x_{1}\right)$, then $S$ has a fixed point.

Proof. Let $x_{0} \in X$ and define

$$
x_{n+1}=S x_{n}, \quad \forall n \geq 0 .
$$

We will assume that $x_{n} \neq x_{n+1}$ for each $n$. Otherwise, there exists an $n$ such that $x_{n}=x_{n+1}$. Then $x_{n}=S x_{n}$ and $x_{n}$ is a fixed point of $S$. Since $\alpha\left(x_{0}, x_{1}\right) \geq \eta\left(x_{0}, x_{1}\right)$ and $S$ is $\alpha$-admissible mapping with respect to $\eta$, we have

$$
\begin{aligned}
\alpha\left(x_{1}, x_{2}\right) & =\alpha\left(S x_{0}, S x_{1}\right) \\
& \geq \eta\left(S x_{0}, S x_{1}\right)=\eta\left(x_{1}, x_{2}\right) .
\end{aligned}
$$

By continuing in this way, we have

$$
\alpha\left(x_{n}, x_{n+1}\right) \geq \eta\left(x_{n}, x_{n+1}\right)
$$

for all $n \in \mathbb{N} \cup\{0\}$. From (43), we have

$$
\alpha\left(x_{n-1}, x_{n}\right) \alpha\left(x_{n}, x_{n+1}\right) \geq \eta\left(x_{n-1}, x_{n}\right) \eta\left(x_{n}, x_{n+1}\right) .
$$

Thus applying the inequality (39), with $x=x_{k-1}$ and $y=x_{k}$, we obtain

$$
\begin{aligned}
& \eta\left(x_{k-1}, S x_{k-1}\right) \eta\left(x_{k}, S x_{k}\right) d\left(x_{k}, x_{k+1}\right) \\
&= \eta\left(x_{k-1}, S x_{k-1}\right) \eta\left(x_{k}, S x_{k}\right) d\left(S x_{k-1}, S x_{k}\right) \\
& \leq \alpha\left(x_{k-1}, S x_{k-1}\right) \alpha\left(x_{k}, S x_{k}\right) d\left(S x_{k-1}, S x_{k}\right) \\
& \leq \eta\left(x_{k-1}, S x_{k-1}\right) \eta\left(x_{k}, S x_{k}\right) \beta\left(d\left(x_{k-1}, x_{k}\right)\right) \\
& \quad \times d\left(x_{k-1}, x_{k}\right)
\end{aligned}
$$

which implies that

$$
d\left(x_{k}, x_{k+1}\right) \leq \beta\left(d\left(x_{k-1}, x_{k}\right)\right) d\left(x_{k-1}, x_{k}\right) .
$$

We suppose that

$$
d\left(x_{k}, x_{k+1}\right) \leq d\left(x_{k-1}, x_{k}\right) .
$$

Then we prove that $d\left(x_{k-1}, x_{k}\right) \rightarrow 0$. It is clear that $\left\{d\left(x_{k-1}\right.\right.$, $\left.\left.x_{k}\right)\right\}$ is a decreasing sequence. Therefore, there exists some positive number $\varrho$ such that $\lim _{n \rightarrow \infty} d\left(x_{k}, x_{k+1}\right)=\varrho$. Now we will prove that $\varrho=0$. From (47), we have

$$
\frac{d\left(x_{k}, x_{k+1}\right)}{d\left(x_{k-1}, x_{k}\right)} \leq \beta\left(d\left(x_{k-1}, x_{k}\right)\right) \leq 1 .
$$

Now by taking limit $k \rightarrow \infty$, we have

$$
\begin{gathered}
1=\frac{d}{d}=\frac{\lim _{k \rightarrow \infty} d\left(x_{k}, x_{k+1}\right)}{\lim _{k \rightarrow \infty} d\left(x_{k-1}, x_{k}\right)} \leq \beta\left(d\left(x_{k-1}, x_{k}\right)\right) \leq 1, \\
\lim _{k \rightarrow \infty} \beta\left(d\left(x_{k-1}, x_{k}\right)\right)=1 .
\end{gathered}
$$

By using property of $\beta$ function, we have $\lim _{k \rightarrow \infty} d\left(x_{k-1}\right.$, $\left.x_{k}\right)=0$. Thus

$$
\lim _{k \rightarrow \infty} d\left(x_{k}, x_{k+1}\right)=0
$$

Now we prove that sequence $\left\{x_{n}\right\}$ is Cauchy sequence. Suppose on contrary that $\left\{x_{n}\right\}$ is not a Cauchy sequence. Then there exists $\epsilon>0$ and sequences $\left\{m_{k}\right\}$ and $\left\{n_{k}\right\}$ such that, for all positive integers $k$, we have $n_{k}>m_{k}>k$,

$$
\begin{gathered}
d\left(x_{m_{k}}, x_{n_{k}}\right) \geq \epsilon, \\
d\left(x_{m_{k}}, x_{n_{k-1}}\right)<\epsilon .
\end{gathered}
$$

By the triangle inequality, we have

$$
\begin{aligned}
\epsilon & \leq d\left(x_{m_{k}}, x_{n_{k}}\right) \\
& \leq d\left(x_{m_{k}}, x_{n_{k-1}}\right)+d\left(x_{n_{k-1}}, x_{n_{k}}\right) \\
& <\epsilon+d\left(x_{n_{k-1}}, x_{n_{k}}\right)
\end{aligned}
$$


for all $k \in \mathbb{N}$. Now taking limit as $k \rightarrow+\infty$ in (52) and using (50), we have

$$
\lim _{k \rightarrow \infty} d\left(x_{m_{k}}, x_{n_{k}}\right)=\epsilon
$$

Again using triangle inequality, we have

$$
\begin{aligned}
d\left(x_{m_{k}}, x_{n_{k}}\right) \leq & d\left(x_{m_{k}}, x_{m_{k+1}}\right)+d\left(x_{m_{k+1}}, x_{n_{k+1}}\right) \\
& +d\left(x_{n_{k+1}}, x_{n_{k}}\right) \\
d\left(x_{m_{k+1}}, x_{n_{k+1}}\right) \leq & d\left(x_{m_{k+1}}, x_{m_{k}}\right)+d\left(x_{m_{k}}, x_{n_{k}}\right) \\
& +d\left(x_{n_{k}}, x_{n_{k+1}}\right) .
\end{aligned}
$$

Taking limit as $k \rightarrow+\infty$ and using (50) and (53), we obtain

$$
\lim _{k \rightarrow+\infty} d\left(x_{m_{k+1}}, x_{n_{k+1}}\right)=\epsilon
$$

By using (39), (53), and (55), we have

$$
\begin{aligned}
& \eta\left(x_{m_{k}}, S x_{m_{k}}\right) \eta\left(x_{n_{k}}, S x_{n_{k}}\right) d\left(x_{m_{k+1}}, x_{n_{k+1}}\right) \\
& \leq \alpha\left(x_{m_{k}}, S x_{m_{k}}\right) \alpha\left(x_{n_{k}}, S x_{n_{k}}\right) d\left(x_{m_{k+1}}, x_{n_{k+1}}\right) \\
& \leq \alpha\left(x_{m_{k}}, S x_{m_{k}}\right) \alpha\left(x_{n_{k}}, S x_{n_{k}}\right) d\left(S x_{m_{k}}, T x_{n_{k}}\right) \\
& \leq \eta\left(x_{m_{k}}, S x_{m_{k}}\right) \eta\left(x_{n_{k}}, S x_{n_{k}}\right) \beta\left(d\left(x_{m_{k}}, x_{n_{k}}\right)\right) \\
& \quad \times d\left(x_{m_{k}}, x_{n_{k}}\right)
\end{aligned}
$$

which implies that

$$
d\left(x_{m_{k+1}}, x_{n_{k+1}}\right) \leq \beta\left(d\left(x_{m_{k}}, x_{n_{k}}\right)\right) d\left(x_{m_{k}}, x_{n_{k}}\right) .
$$

Therfore, we have

$$
\frac{d\left(x_{m_{k+1}}, x_{n_{k+1}}\right)}{d\left(x_{m_{k}}, x_{n_{k}}\right)} \leq \beta\left(d\left(x_{m_{k}}, x_{n_{k}}\right)\right) \leq 1 .
$$

Now taking limit as $k \rightarrow+\infty$ in (58), we get

$$
\lim _{n \rightarrow \infty} \beta\left(d\left(x_{m_{k}}, x_{n_{k}}\right)\right)=1
$$

Hence $\lim _{k \rightarrow \infty} d\left(x_{m_{k}}, x_{n_{k}}\right)=0<\epsilon$, which is a contradiction. Hence $\left\{x_{n}\right\}$ is a Cauchy sequence. Since $X$ is complete so there exists $p \in X$ such that $x_{n} \rightarrow p$. Now we prove that $p=S p$. Suppose (i) holds; that is, $S$ is continuous, so we get

$$
S p=S \lim _{n \rightarrow \infty} x_{n}=\lim _{n \rightarrow \infty} S x_{n}=\lim _{n \rightarrow \infty} x_{n+1}=p .
$$

Thus $p=S p$. Now we suppose that (ii) holds. Since

$$
\alpha\left(x_{n}, x_{n+1}\right) \geq \eta\left(x_{n}, x_{n+1}\right)
$$

for all $n \in \mathbb{N} \cup\{0\}$. By the hypotheses of (ii), we have

$$
\alpha(p, S p) \alpha\left(x_{k}, S x_{k}\right) \geq \eta(p, S p) \eta\left(x_{k}, S x_{k}\right) .
$$

Using the triangle inequality and (39), we have

$$
\begin{aligned}
& \eta(p, S p) \eta\left(x_{k}, S x_{k}\right) d\left(S p, x_{k+1}\right) \\
& \quad=\eta(p, S p) \eta\left(x_{k}, S x_{k}\right) d\left(S p, S x_{k}\right) \\
& \quad \leq \alpha(p, S p) \alpha\left(x_{k}, S x_{k}\right) d\left(S p, S x_{k}\right) \\
& \quad \leq \eta(p, S p) \eta\left(x_{k}, S x_{k}\right) \beta\left(d\left(p, x_{k}\right)\right) d\left(p, x_{k}\right),
\end{aligned}
$$

which implies that

$$
d\left(S p, x_{k+1}\right) \leq \beta\left(d\left(p, x_{k}\right)\right) d\left(p, x_{k}\right) .
$$

Letting $k \rightarrow \infty$, we have $d(p, S p)=0$. Thus $p=S p$. Let there exists $q$ to be another fixed point of $S q \in X$, s.t $q=S q$;

$$
\begin{aligned}
& \eta(p, S p) \eta(q, S q) d(S p, S q) \\
& \quad \leq \alpha(p, S p) \alpha(q, S q) d(S p, S q) \\
& \quad \leq \eta(p, S p) \eta(q, S q) \beta(d(p, q)) d(p, q),
\end{aligned}
$$

implies

$$
d(S p, S q) \leq \beta(d(p, q)) d(p, q)
$$

By the property of $\beta$ function, $\beta(d(p, q))=1$ implies $d(p$, $q)=0$; then we have $p=q$. Hence $S$ has a unique fixed point. lary.

If $\eta(x, y)=1$ in Theorem 10, we get the following corol-

Corollary 11 (see [17]). Let $(X, d)$ be a complete metric space and let $S$ be $\alpha$-admissible mapping. Assume that there exists a function $\beta:[0,+\infty) \rightarrow[0,1)$ such that, for any bounded sequence $\left\{t_{n}\right\}$ of positive reals, $\beta\left(t_{n}\right) \rightarrow 1$ implies $t_{n} \rightarrow 0$ such that

$$
\alpha(x, S x) \alpha(y, S y) d(S x, S y) \leq \beta(d(x, y)) d(x, y)
$$

for all $x, y \in X$. Suppose that either

(i) $S$ is continuous, or

(ii) if $\left\{x_{n}\right\}$ is a sequence in $X$ such that $\alpha\left(x_{n}, x_{n+1}\right) \geq 1$ for all $n \in \mathbb{N} \cup\{0\}$ and $x_{n} \rightarrow p \in X$ as $n \rightarrow+\infty$, then

$$
\alpha(p, S p) \geq 1 \text {. }
$$

If there exists $x_{0}, x_{1} \in X$ such that $\alpha\left(x_{0}, x_{1}\right) \geq 1$, then $S$ has a fixed point. Our results are more general than those in [17, 32, 33 ] and improve several results existing in the literature.

\section{Conflict of Interests}

The authors declare that they have no competing interests.

\section{Authors' Contribution}

All authors contributed equally and significantly to writing this paper. All authors read and approved the final paper. 


\section{Acknowledgments}

Marwan Amin Kutbi gratefully acknowledges the support from the Deanship of Scientific Research (DSR) at King Abdulaziz University (KAU) during this research. The authors thank the editor and the referees for their valuable comments and suggestions which improved greatly the quality of this paper.

\section{References}

[1] M. Abbas and B. E. Rhoades, "Common fixed point theorems for hybrid pairs of occasionally weakly compatible mappings satisfying generalized contractive condition of integral type," Fixed Point Theory and Applications, vol. 2007, Article ID 54101, 9 pages, 2007.

[2] M. Abbas and B. E. Rhoades, "Common fixed point theorems for occasionally weakly compatible mappings satisfying a generalized contractive condition," Mathematical Communications, vol. 13, no. 2, pp. 295-301, 2008.

[3] M. Abbas and A. R. Khan, "Common fixed points of generalized contractive hybrid pairs in symmetric spaces," Fixed Point Theory and Applications, vol. 2009, Article ID 869407, 11 pages, 2009.

[4] T. Abdeljawad, "Meir-Keeler $\alpha$-contractive fixed and common fixed point theorems," Fixed Point Theory and Applications, vol. 2013, article 19, 2013.

[5] A. Aliouche, "A common fixed point theorem for weakly compatible mappings in symmetric spaces satisfying a contractive condition of integral type," Journal of Mathematical Analysis and Applications, vol. 322, no. 2, pp. 796-802, 2006.

[6] M. Arshad, "Some fixed point results for $\alpha^{*}-\psi$-contractive multi-valued mapping in partial metric spaces," Journal of Advanced Research in Applied Mathematics. In press.

[7] M. Arshad, A. Azam, and P. Vetro, "Some common fixed point results in cone metric spaces," Fixed Point Theory and Applications, vol. 2009, Article ID 493965, 11 pages, 2009.

[8] S. Banach, "Sur les opérations dans les ensembles abstraits et leur application aux équations intégrales," Fundamenta Mathematicae, vol. 3, pp. 133-181, 1922.

[9] A. Branciari, "A fixed point theorem for mappings satisfying a general contractive condition of integral type," International Journal of Mathematics and Mathematical Sciences, vol. 29, no. 9, pp. 531-536, 2002.

[10] E. Karapinar and B. Samet, "Generalized $(\alpha-\psi)$ contractive type mappings and related fixed point theorems with applications," Abstract and Applied Analysis, vol. 2012, Article ID 793486, 17 pages, 2012.

[11] U. C. Gairola and A. S. Rawat, "A fixed point theorem for integral type inequality," International Journal of Mathematical Analysis, vol. 2, no. 13-16, pp. 709-712, 2008.

[12] M. A. Geraghty, "On contractive mappings," Proceedings of the American Mathematical Society, vol. 40, pp. 604-608, 1973.

[13] F. Gu and H. Ye, "Common fixed point theorems of Altman integral type mappings in G-metric spaces," Abstract and Applied Analysis, vol. 2012, Article ID 630457, 13 pages, 2012.

[14] V. Gupta and N. Mani, "A common fixed point theorem for two weakly compatible mappings satisfying a new contractive condition of integral type," Mathematical Theory and Modeling, vol. 1, no. 1, 2011.
[15] R. H. Haghi, S. Rezapour, and N. Shahzad, "Some fixed point generalizations are not real generalizations," Nonlinear Analysis, vol. 74, no. 5, pp. 1799-1803, 2011.

[16] N. Hussain, M. Arshad, and A. Shoaib, "Shoaib and Fahimuddin, Common fixed point results for $\alpha-\psi$-contractions on a metric space endowed with graph," Journal of Inequalities and Applications, vol. 2014, article 136, 2014.

[17] N. Hussain, E. Karapınar, P. Salimi, and F. Akbar, " $\alpha$-admissible mappings and related fixed point theorems," Journal of Inequalities and Applications, vol. 2013, article 114, 11 pages, 2013.

[18] N. Hussain and M. Abbas, "Common fixed point results for two new classes of hybrid pairs in symmetric spaces," Applied Mathematics and Computation, vol. 218, no. 2, pp. 542-547, 2011.

[19] N. Hussain and Y. J. Cho, "Weak contractions, common fixed points, and invariant approximations," Journal of Inequalities and Applications, vol. 2009, Article ID 390634, 10 pages, 2009.

[20] G. Jungck and B. E. Rhoades, "Fixed points for set valued functions without continuity," Indian Journal of Pure and Applied Mathematics, vol. 29, no. 3, pp. 227-238, 1998.

[21] G. Jungck and N. Hussain, "Compatible maps and invariant approximations," Journal of Mathematical Analysis and Applications, vol. 325, no. 2, pp. 1003-1012, 2007.

[22] G. Jungck and B. E. Rhoades, "Fixed point theorems for occasionally weakly compatible mappings," Fixed Point Theory, vol. 7, no. 2, pp. 287-296, 2006.

[23] G. Jungck and B. E. Rhoades, "Erratum: "Fixed point theorems for occasionally weakly compatible mappings" [Fixed Point Theory, vol. 7 (2006), no. 2, 287-296]," Fixed Point Theory, vol. 9, no. 1, pp. 383-384, 2008.

[24] R. Kannan, "Some results on fixed points," Bulletin of the Calcutta Mathematical Society, vol. 60, pp. 71-76, 1968.

[25] S. Moradi and M. Omid, "A fixed point theorem for integral type inequality depending on another function," Research Journal of Applied Sciences, Engineering and Technology, vol. 2, no. 3, pp. 239-2442, 2010.

[26] S. B. Nadler, "Multi-valued contraction mappings," Pacific Journal of Mathematics, vol. 30, pp. 475-488, 1969.

[27] D. B. Ojha, M. K. Mishra, and U. Katoch, "A common fixed point theorem satisfying integral type for occasionally weakly compatible maps," Research Journal of Applied Sciences, Engineering and Technology, vol. 2, no. 3, pp. 239-244, 2010.

[28] H. K. Pathak, R. Tiwari, and M. S. Khan, "A common fixed point theorem satisfying integral type implicit relations," Applied Mathematics E-Notes, vol. 7, pp. 222-228, 2007.

[29] B. E. Rhoades, "A comparison of various definitions of contractive mappings," Transactions of the American Mathematical Society, vol. 226, pp. 257-290, 1977.

[30] B. E. Rhoades, "Two fixed-point theorems for mappings satisfying a general contractive condition of integral type," International Journal of Mathematics and Mathematical Sciences, no. 63, pp. 4007-4013, 2003.

[31] P. K. Shrivastava, N. P. S. Bawa, and S. K. Nigam, "Fixed point theorems for hybrid contractions," Varahmihir Journal of Mathematical Sciences, vol. 2, no. 2, pp. 275-281, 2002.

[32] P. Salimi, A. Latif, and N. Hussain, "Modified $\alpha-\psi$-contractive mappings with applications," Fixed Point Theory and Applications, vol. 2013, 19 pages, 2013. 
[33] B. Samet, C. Vetro, and P. Vetro, "Fixed point theorems for $\alpha-\psi$-contractive type mappings," Nonlinear Analysis: Theory, Methods \& Applications, vol. 75, no. 4, pp. 2154-2165, 2012.

[34] P. Vijayaraju, B. E. Rhoades, and R. Mohanraj, "A fixed point theorem for a pair of maps satisfying a general contractive condition of integral type," International Journal of Mathematics and Mathematical Sciences, no. 15, pp. 2359-2364, 2005.

[35] Y. Li and F. Gu, "Common fixed point theorem of altman integral type mappings," Journal of Nonlinear Science and Its Applications, vol. 2, no. 4, pp. 214-218, 2009.

[36] X. Zhang, "Common fixed point theorems for some new generalized contractive type mappings," Journal of Mathematical Analysis and Applications, vol. 333, no. 2, pp. 780-786, 2007. 


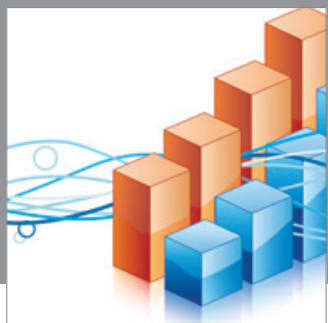

Advances in

Operations Research

mansans

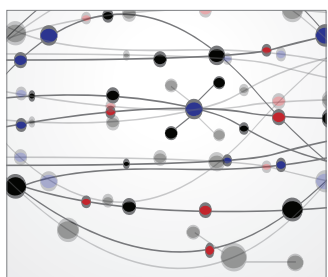

The Scientific World Journal
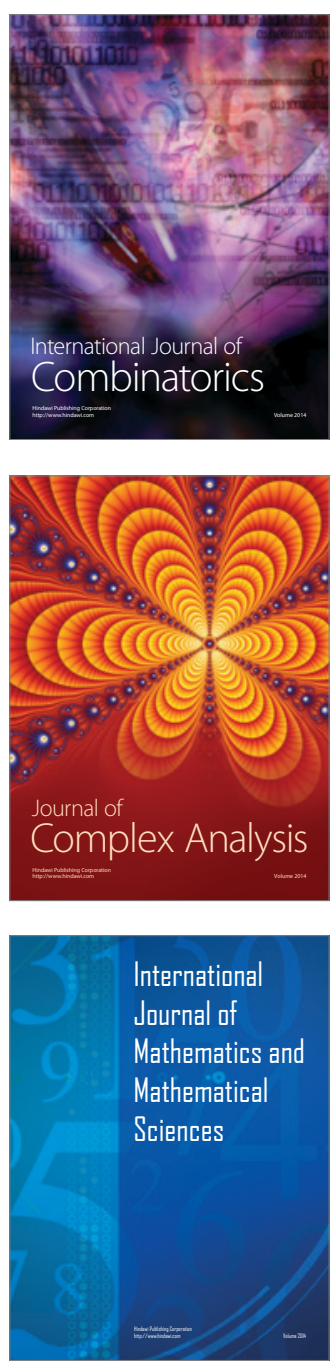
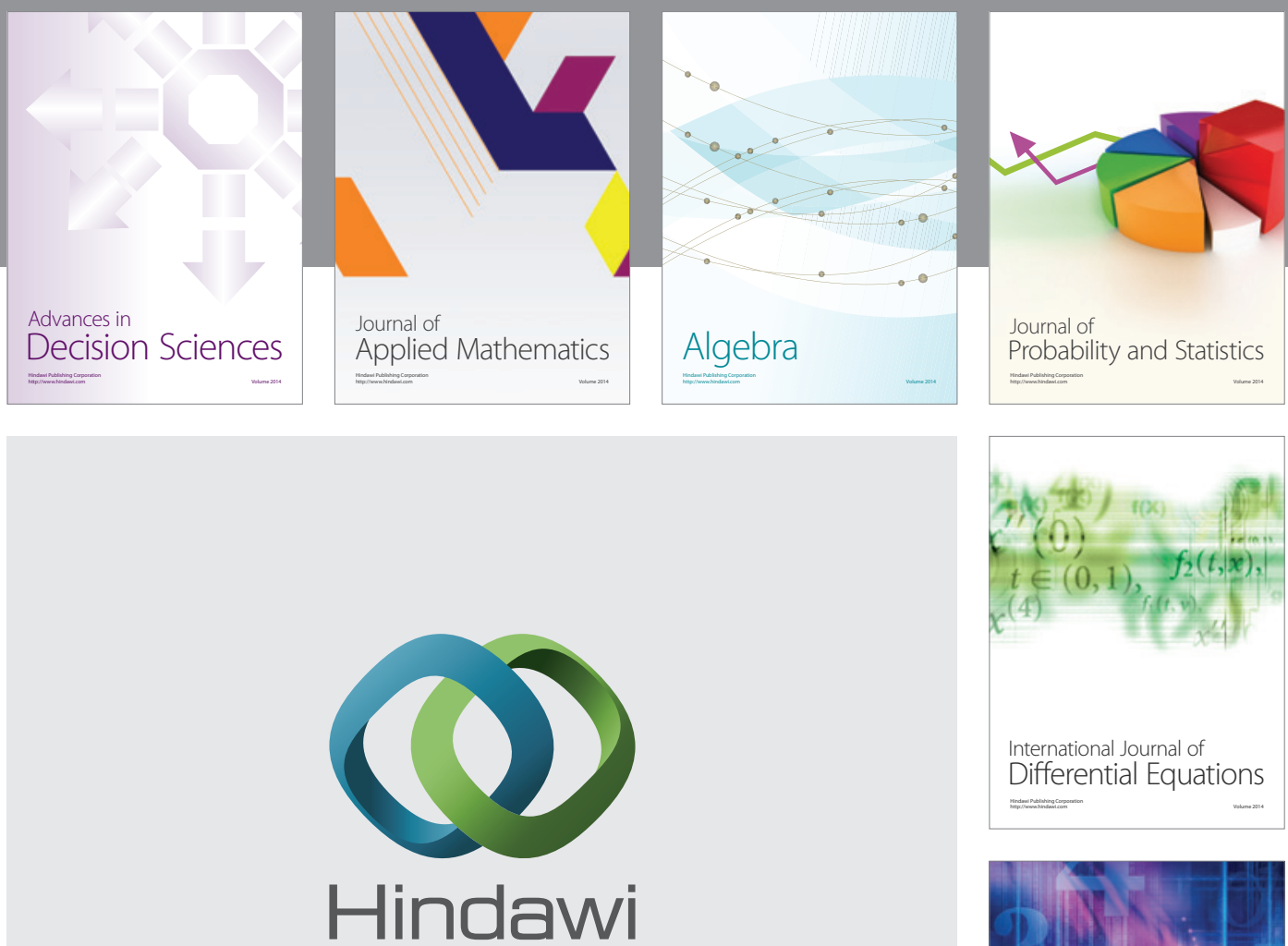

Submit your manuscripts at http://www.hindawi.com
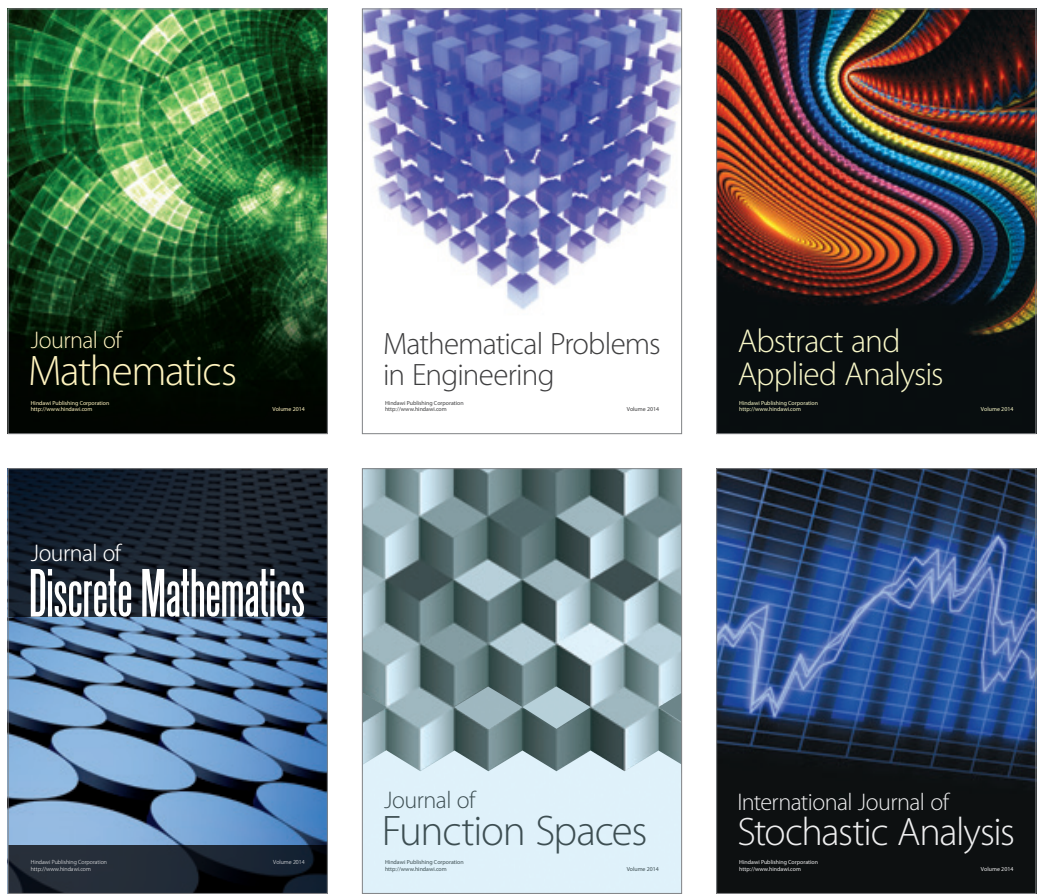

Journal of

Function Spaces

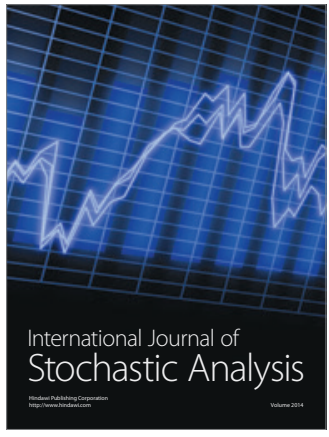

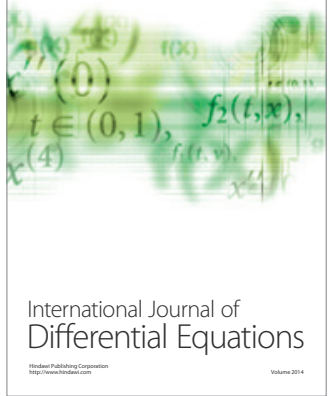
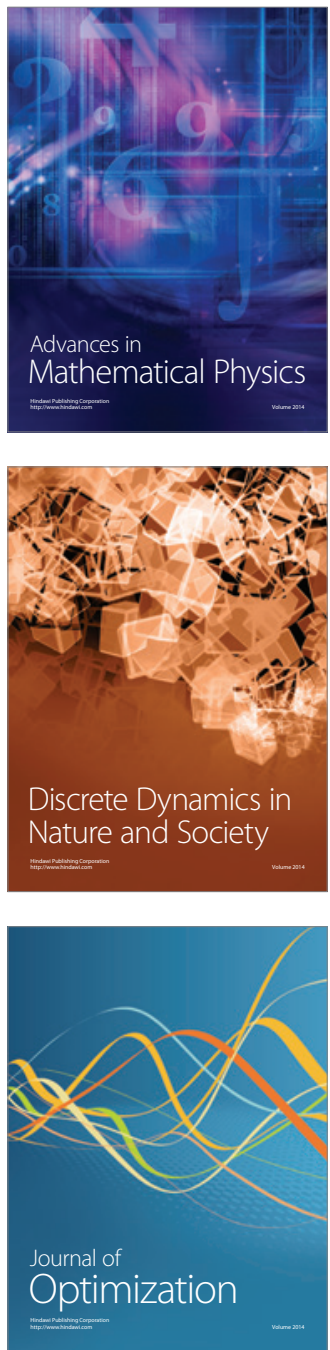